\title{
Getting Back To Exercise Without Pain: The Ankle \\ part II.
}

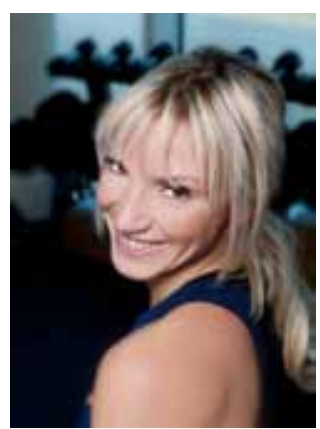

Authors: JUDIT RESSINKA

Title: Personal Trainer, Strength \& Conditioning Coach

Workplace: Crowne Plaza Battersea e-mail: juditressinka@yahoo.co.uk Webpage: www.movepainfree.co.uk Picture, figure: JUDIT RESINKA Other-outhors: PÉTER FRITZ, ZOLTÁN SZATMÁRI

Abstract: Physical activity is becoming an increasingly popular lifestyle choice as people are encouraged to make healthier choices. For most people, this means balancing exercise with a working day that typically requires them to be sitting for 10 to 12 hours which lessens the ability of the body to effectively take part in recreational and sporting activities, and leads to repetitive strain injuries, postural deviations and musculoskeletal problems $(8,16,27)$. Therefore, the desire of the modern client to combine extended periods of inactivity with increasingly demanding exercise routines, such as marathon running, are becoming a growing challenge for personal trainers and sports coaches.

Such issues occur because muscles have the tendency to become underactive or overactive when engaged by certain repetitive postures and activities $(20,27)$. For example, sitting, driving or wearing high heels can encourage the ankle dorsiflexors to weaken, the plantarflexors to become overactive, while it is also suggested that there will be interrelated, global impairments and consequences of this at the more proximal joints such as the knees and hips $(11,12,14,19,23,24,30)$. Achilles tendinopathy $(1,31)$, plantar fasciitis $(18)$ and shin splints $(30,33)$ are some of the most common sports injuries of the ankle among runners and those participating in sports that involve jumping.

As coaches, we shouldn't be diagnosing injuries, but helping to prevent the occurrence of them, by looking for common lower extremity alignments, muscle weaknesses and movement deviations. This article focuses on the evaluation of movement, the scanning of misalignments and the introduction of corrective exercises using the NASM Corrective Exercise Continuum (Cex) (7), which is based on deactivation and activation techniques of the neuromyofactial tissue (7). Using CEx with my clients - in conjunction with body and postural awareness techniques - has enabled them to eliminate some musculoskeletal problems.

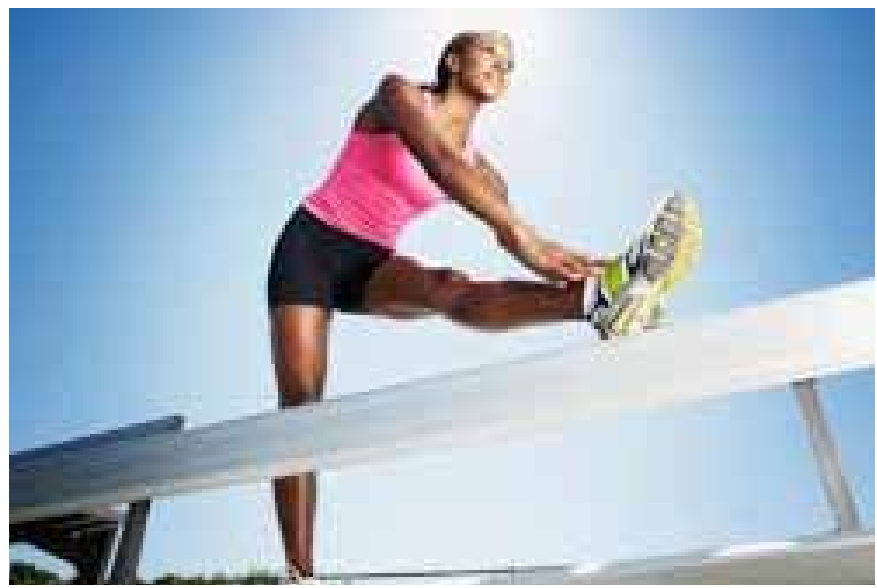

[Figure1]
Keywords: ankle dorsiflexion, medial knee displacement, overpronation, hip adductor, the NASM Corrective Exercise Continuum,

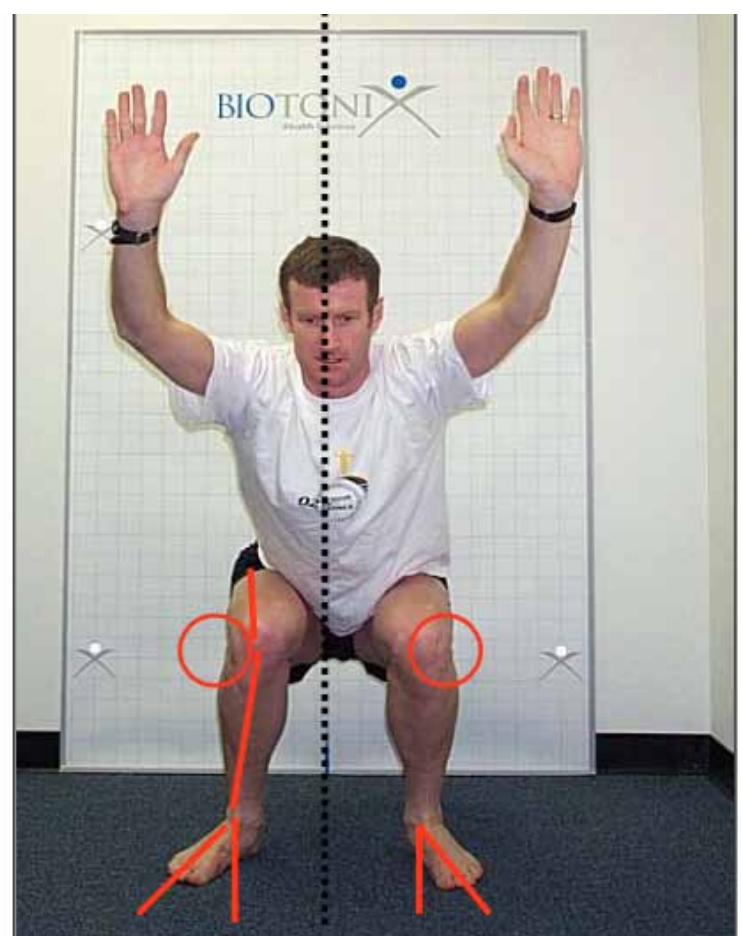

Figure 11. Overhead squat test: out-toeing and excessive medial knee displacement

\section{Further testing:}

- Add a wedge under the heel if knee collapses in, if the knee tracks forward and toing out disappears the calves could be too tight. Prescribe deactivation of the calves and stretch the tight parts of the calves.

- Manual Muscle Test glutesusmaximus, gluteus medius strength (see article about the knee $(7,27)$

- Manual Muscle Test posterior tibialis and/or anterior tibialis $(7,20)$

- Length test adductor muscles (27)

\section{NASM CEx for injury prevention at the ankle - Corrective exercise strategy}

Achieving relaxation and lengthening of the gastrocnemius and soleus and hip adductor muscles to facilitate increased ankle dorsiflexion and hip abduction strength improvements are the most common goals of our intervention.

As the gluteus maximus and gluteus medius are both involved in frontal plane knee alignment and ankle stability, both hips and ankles have been shown to be connected to ACL injuries, patellar tendinopathy and PFPS. Strengthening of these muscles and the ankle muscles is therefore a primary goal in both the prevention and rehabilitation of these injuries. The results of many studies indicate that the single leg squat may be the most effective exercise both for activating the hip abductors and extensors $(6,8,22,25,26,32,34)$ and the ankle muscles. 


\begin{tabular}{|c|c|c|}
\hline Exerche Sequence & Foeus & Exerelise Fronosed \\
\hline 1) lanait tight/overactive muscle & $\begin{array}{l}\text { Gastrochemius/solevu, persocals, his } \\
\text { astuctons }\end{array}$ & fosm roll each for 2 minutes \\
\hline 2) Lengthen tight/overactive muscles & 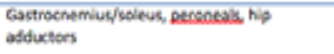 & $\begin{array}{l}\text { Static Strecth for } 2 \text { sets of } 30 \\
\text { neconds }\end{array}$ \\
\hline 3) Streng then wesk/underactive mulcles & 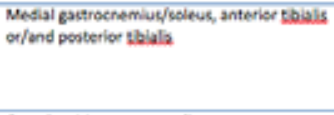 & 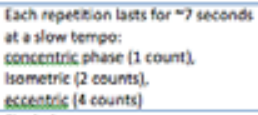 \\
\hline 4) lobeceation earrches & Co-plex, Morement quality & 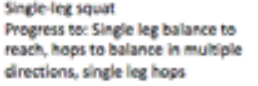 \\
\hline
\end{tabular}

Table 1

Warm up with 10 minutes of very light jogging, cycling, elliptical-trainer work, or stair-stepper action.

\section{Step 1: Self-Myofascial Release (SMR)}

Look for tender knots using a foam roller or ball and roll over the muscle. Hold as close to the tension area as possible for 30 to 45 seconds or if the pain is too intense, hold for 90 seconds with lower intensity. Repeat for increased effectiveness. If an area really hurts, transfer more body weight to your arms as you support yourself on them. More bodyweight can be moved to the area as the muscle begins to relax.

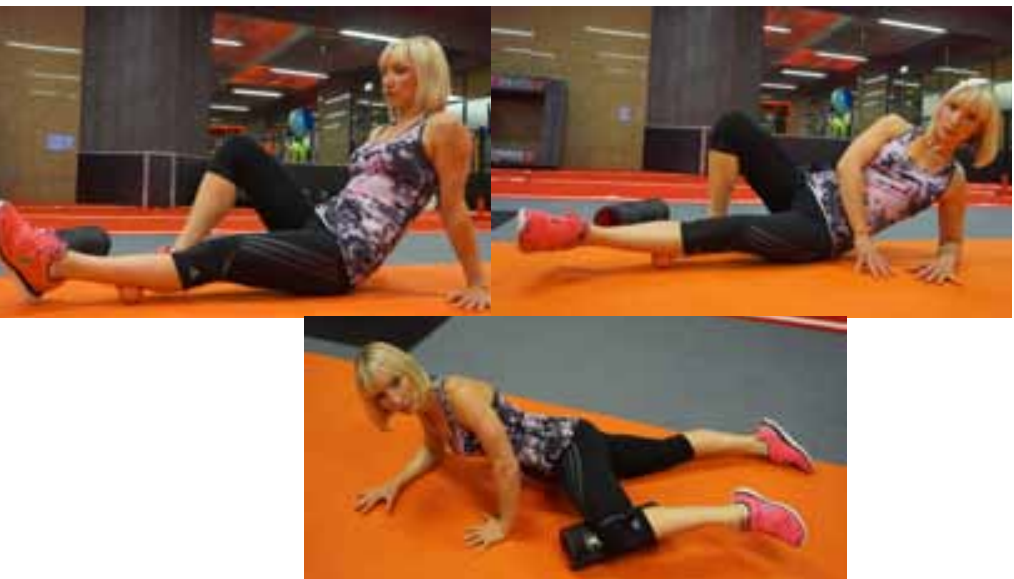

Figure 12. SMR a) calf b) peroneals, c) adductors

\section{Step 2: Static and Dynamic Stretches}

I advise clients to do static stretches after their workouts. However, if a muscle is tight - in particular to the calf muscles, they should stretch these before their workout to enable greater range of movement. While stretching, the client should breath deeply and hold each stretch for 1530 seconds, repeating if possible and only to the edge of discomfort - on a scale of 1-10, aim for 7-8.

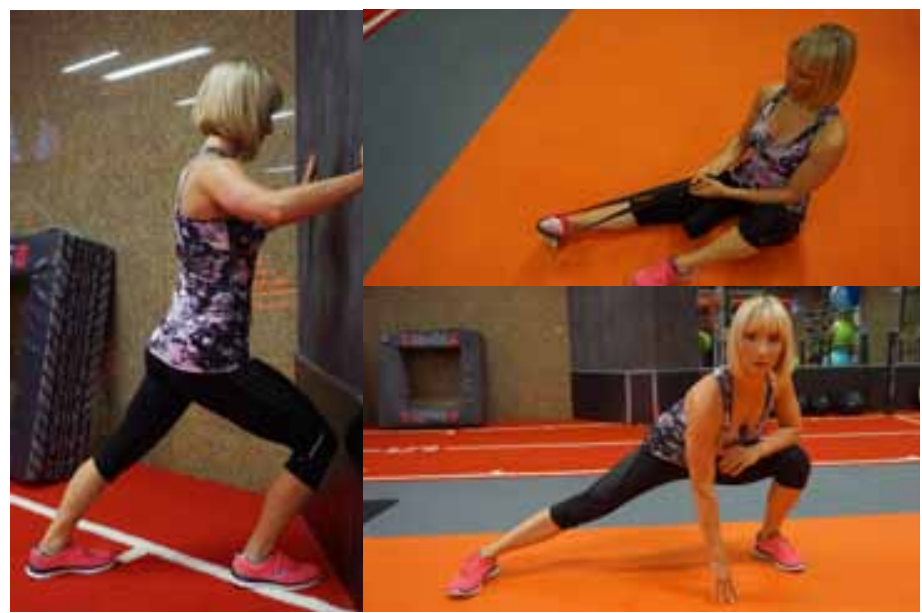

Figure 13.a) dynamic calf stretch, b) peroneal stretchc) adductor stretch

\section{Step 3: Isolation Exercises}

Once the release and lengthening of tight muscles has been achieved, activation can be done through isolation exercises. These involve only one joint and a limited number of muscle groups, so that more attention can be paid to ensuring the muscle's sufficient contraction - thereby avoiding using the overactive, 'cheating' muscles. Isolation exercises are slow and controlled motions.

2-3 sets of 12-15 repetitions with a 2-second hold

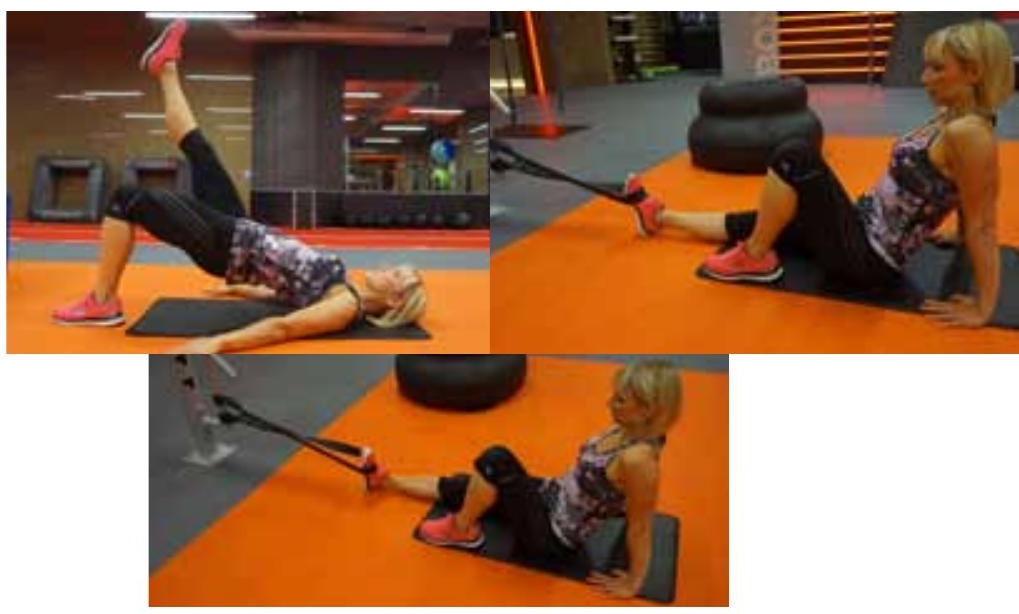

Figure 14. a) single leg bridge gluteal activation, anterior tibialisstrengthening with band start b) and finish c)

\section{Step 4: Integration}

The single leg squat is designed to promote hip and ankle stability. This type of exercise requires the hips to stabilize against the hip adduction/ internal rotation forces. Clueing the client with the right alignment is very important otherwise he or she will not have a positive experience.

2-3 sets of 10-15 repetitions on each leg.

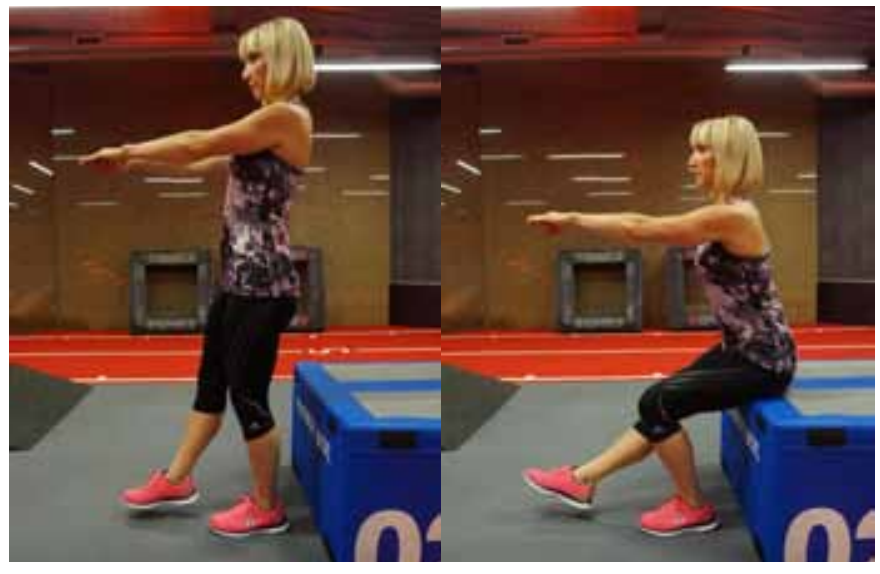

Figure 15. Single leg squat start a) and finish b)

\section{Conclusion}

There are some obvious signs that can be spotted while performing single leg squats, overhead squats and landing tasks, which will point the trainer, where to look for limitations. The turn out feet, heel raises or knee valgus would prompt an experienced practitioner to check for calf tightness, which greatly limits ankle dorsiflexion.

It is apparent however, that multiple factors can influence foot pronation and frontal plane knee biomechanics and, ultimately, ankle and knee injury risk. The evidence shows that regaining normal ankle dorsiflexion range and increased hip abductor activation are two components that 
can help to prevent or rehabilitate ankle and knee injuries. Given the associations between overpronation of the foot with increased hip adductor activation, this then also should be addressed in programs designed to improve excessive pronation.

A global view that takes into consideration the joints below and above the ankle is therefore required. Subsequently, the integration of specific exercises to address all of these components (Figure...) may be needed to optimize the programs. Trainers should perform visual and manual muscle tests to decide which of these exercises are absolutely needed for that individual.

\section{Footnote}

While exercising, is generally helpful to reduce excessive pronation, some individuals may have structural skeletal pathologies that warrant the use of corrective devices like orthotics. Work with a licensed health care practitioner to determine the best option to ensure your safety and help you achieve the best results. Please consult a doctor if you have any unusual symptoms doing any of these exercises. Foam rolling should be avoided if you have unhealed wounds, bone fractures, skin cancer, osteoporosis, high blood pressure or any others strains or sprains. It is not advised to roll on an area that is affected by varicose veins and broken capillaries. While performing these exercises, please be aware of good body positioning and control of movement.

\section{References}

1. Azevedo L.B.,Lambert M.I., Vaughan C.L., O'Connor C.M., Schwellnus M.P. (2009): Biomechanical variables associated with Achilles tendinopathy in runners. Br J Sports Med. 43(4):288-92.

2. Backman, L.J., Danielson, P. (2011): Low range of ankle dorsiflexion predisposes for Patellar Tendinopathy in Junior Elite Basketball Players a 1-Year prospective study. Am J Sports Med. 39:2626-2633.

3. Bell D.R., Padua D.A., \& Clark M.A. (2008): Muscle strength and flexibility characteristics of people displaying excessive medial knee displacement. Arch Phys Med Rehabil 89(7):1323-1328

4. Bell D.R., Vesci B.J., \&DiStefano L.J. (2011): Muscle activity and flexibility in individuals with medial knee displacement during the overhead squat. Athl Train Sports Health Care. 4(3):117-125. 20110817-03.

5. Bullock-Saxton J.E.,Janda V., \&Bullock M.I. (1994): The influence of ankle sprain injury on muscle activation during hip extension. Int J Sports Med. 15(6):330-4.

6. Claiborne T.L., Armstrong C.W., Gandhi V., Pincivero, D.M. (2006): Relationship between hip and knee strength and knee valgus during a single leg squat. $J$ ApplBiomech. 22: 41-50

7. Clark M.A. \&Lucett S.C. (2011): NASM Essentials of Corrective Exercise Training. Lippincott Williams \& Wilkins, United States. pp252-265,280.

8. Davies, S.C., McBride, M., Keel, A., Hussey R. (2014): Musculoskeletal health: Public Health Approach. www.arthritisresearchuk.org/ /media/Files/.../publichealth-guide.ashx

9. Devita P., \& Skelly W.A. (1992): Effect of landing stiffness on joint kinetics and energetics in the lower extremity. Med Sci Sports Exerc. 24(1):108-115.

10. Dill K.E.,Begalle R.L., Frank B.S., Zinder S.M., Padua D.A. (2014): Altered knee and ankle kinematics during squatting in those with limited weight-bearing-lunge ankle-dorsiflexion range of motion. J Athl Train. 49(6):723-32.

11. Earl J.E. \&Hoch A.Z. (2011): A proximal strengthening program improves pain, function, and biomechanics in women with patellofemoral pain syndrome. Am J Sports Med. 39(1):154-63.

12. Fong C.M.,Blackburn J.T., Norcross M.F., McGrath M., Padua D.A. (2011): Ankle-dorsiflexion range of motion and landing biomechanics. JAthl Train. 46(1):510.

13. Graf A., Judge J.O. \&Ounpuu S. (2005): The effect of walking speed on lower- extremity joint powers among elderly adults who exhibit low physical performance. Arch Phys Med Rehabil. 86(11):2177-83.

14. Hewett T.E. (2005): Anterior cruciate ligament injuries in female athletes: Part 2 , a meta-analysis of neuromuscular interventions aimed at injury prevention. Am J Sports Med. 34(3):490-498.

15. Hirth C.J. \& Padua D.A. (2007): Clinical movement analysis to identify muscle imbalances and guide exercise. AthlTher Today. 12: 10-14.

16. Holth H.S., Werpen H.K.B., Zwart J.A., Hagen K. (2008): Physical inactivity is associated with chronic musculoskeletal complaints 11 years later: Results from the Nord-Trondelag Health Study. BMC MusculoskelDisord. 9:159.

17. Huberti H.H. \&Hayes,W.C. (1984): Patellofemoral contact pressures(The influence of $Q$-angle and tendofemoral contact . J Bone Joint Surg Am. 66: 715724.

18. Irving D.B.,Cook J.L, Menz H.B. (2006): Factors associated with chronic plantar heel pain: a systematic review. J Sci Med Sport. 9(1-2):11-22.

19. Jonkers I., Delp S., \& Patten C. (2009): Capacity to increase walking speed is limited by impaired hip and ankle power generation in lower functioning persons post-stroke. Gait Posture. 29(1):129-37.

20. Kendall F.P., McKCreary E.K. and Provance P.G. (2005): Muscle Testing and Function with Posture and Pain. 5th ed. Lippincott Williams and Wilkins, Baltimore, MD. pp19-22, 35, 50-54, 410-411.

21. Lee T.Q., Yang B.Y., Sandusky M.D., McMahon P.J. (2001): The effects of tibial rotation on the patellofemoral joint: assessment of the changes in in situ strain in the peripatellar retinaculum and the patellofemoral contact pressures and areas. J Rehabil Res Dev. 38: 463-469.

22. Lubahn, A.J., Kernozek T. W., Tyson T.L.,Merkitch K.W. Reutemann P., Chestnut J.M. (2011): Hip muscle activation and knee frontal plane motion during weight bearing therapeutic exercises. Int J Sports PhysTher. 6(2): 92-103.

23. Macrum E.,Bell D.R., Boling M., Lewek M., Padua D. (2012): Effect of limiting ankle-dorsiflexion range of motion on lower extremity kinematics and muscleactivation patterns during a squat. J Sport Rehabil. 21(2):144-50.

24. Mauntel T.C.,Begalle R.L., Cram T.R., Frank B.S., Hirth C.J., Blackburn T., Padua D.A. (2013): The effects of lower extremity muscle activation and passive range of motion on single leg squat performance. J Strength Cond Res. 27(7):1813-23.

25. Mizuno Y., Kumagai M., Mattessich S.M. (2001): Q-angle influences tibiofemoral and patellofemoral kinematics. J Orthop Res. 19(5):834-840.

26. Padua D.A., Bell D.R., \& Clark M.A. (2012): Neuromuscular characteristics of individuals displaying excessive medial knee displacement. J Athl Train 47(5):525536.

27. Page P., Clare C.F., and Ladner R. (2010): Assessment and Treatment of Muscle Imbalance. The Janda Approach. Human Kinetics, p89-90,98.

28. Paterno M.V., Schmitt L.C., Ford K.R. (2010): Biomechanical measures during landing and postural stability predict second anterior cruciate ligament injury after anterior cruciate ligament reconstruction and return to sport. Am J Sports Med. 38(10):1968-1978.

29. Powers C.M. (2003): The influence of altered lower-extremity kinematics on patellofemoral joint dysfunction: a theoretical perspective. J Orthop Sports PhysTher. 33(11):639-46.

30. Rao S., Riskowski J., Hannan M.T. (2012): Musculoskeletal Conditions of the Foot and Ankle: Assessments and Treatment Options. Best Pract Res ClinRheumatol. 26(3): 345-368.

31. Rees J.D.,Maffulli N., Cook J. (2009): Management of tendinopathy. Am J Sports Med. 37(9):1855-67.

32. Snyder K.R. Earl J.E.,O'Connor K.M., Ebersole K.T. (2008): Resistance training is accompanied by increases in hip strength and changes in lower extremity biomechanics during running. ClinBiomech. 24(1):26-34.

33. Tweed J.L.,Campbell J.A., Avil S.J. (2008): Biomechanical risk factors in the development of medial tibial stress syndrome in distance runners. J Am Podiatr Med Assoc. 98(6):436-44.

34. Willson J.D., Ireland M.L., \& Davis, I. (2006): Core strength and lower extremity alignment during single leg squats. Med Sci Sports Exerc. 38: 945-952. 